\section{Performance of Broilers Fed Increased Levels Energy in the Pre-Starter Diet and on Subsequent Feeding Programs Having with Acidulated Soybean Soapstock Supplementation}

Duthor(s)

Vieira SL

Viola ES

Berres J

Olmos AR

Conde ORA

Almeida JG

Departamento de Zootecnia

Universidade Federal do Rio Grande do Sul

\section{Mail Address}

Sérgio Luiz Vieira

Universidade Federal do Rio Grande do Sul

Av. Bento Gonçalves, 7712

91.540-000. Porto Alegre, RS, Brasil

Telephone: 555133166048

FAX: $\quad 555133166039$

E-mail: slvieira@ufrgs.br

\section{Keywords}

Fat, pre-starter diet, soybean fat.

This research was supported by FAPERGS.

\section{ABSTRACT}

This study aimed to evaluate broiler responses to increases in feed energy $(2,870,3,000$ and 3,100 kcal ME/ $\mathrm{kg})$ and the inclusion of Acidulated Soybean Soapstock (ASS) when compared to Degummed Soybean Oil (DSO) in feeds from placement to 7 days of age. From 7 to 42 days ASS or DSO were included in diets that contained similar energy and nutrient levels. Metabolizable energy values used to formulate the diets for ASS and DSO were 8,351 and 7,701 kcal ME/kg in the first week and 9,314 and 8,559 kcal ME/kg afterwards, respectively. Diets were based on corn and soybean meal and were fed to 1,600 one-dold male broiler chicks randomly placed in 40 floor pens. No differences in performance due to fat source were seen at 7 days. However, the increase in energy levels to 3,100 kcal ME/kg reduced feed intake, whereas feed conversion was improved with energy at 3,000 kcal ME/ $\mathrm{kg}$. Live performance, and the yields of carcass and commercial cuts were not affected by the type of fat included in the feeds from 7 to 42 days, except for increased body weight at 21 and 35 days with ASS supplementation. Litter moisture at 7, 21, 35 and 42 days was not affected by any of the factors and there were no residual effects of treatments at 21, 35 and 42 days of age. On the other hand, body weight at 35 days was affected by the interaction of diets fed in the first week with those provided afterwards. The results showed that ME values used for DSO and ASS are adequate and that ASS may be used as fat source in broiler feeds from placement to 42 days of age.

\section{INTRODUCTION}

Acidulated soapstock is a fat source produced by the acidification of residues produced during the refining of vegetal oil for human consumption. Several types of soapstock have been used in broiler feeding, and are composed either of a unique source or blends of different fats. Soapstocks have high free fatty acid content. Acidulated Soybean Soapstock (ASS), for example, is composed by around 70\% free fatty acids compared to less than $1 \%$ in soybean oil (Lipstein \& Bornstein, 1968). However, similar fatty acid profiles are expected for soapstocks and vegetal neutral fats, as long as they are derived from the same source.

Fat utilization by post hatchings chicks seems to depend on transportation by lipoproteins from maternal origin or synthesized in the yolk (Sklan, 2003). However, glucose becomes the main energy source in older birds with the increased intestinal uptake. Concurrently, adequate utilization of neutral fats from feeds is only achievable through emulsification by bile and further hydrolysis to monoglycerides and free fatty acids. The efficiency of this process depends not only on the presence of monoglycerides and on the extension and saturation of the 
Vieira SL, Viola ES, Berres J, Olmos AR, Conde ORA, Almeida JG
Performance of Broilers Fed Increased Levels Energy in the Pre-Starter Diet and on Subsequent Feeding Programs Having with Acidulated Soybean Soapstock Supplementation fatty acid chain, but also on the ability to secrete active pancreatic lipase (Hoffman \& Borgström, 1962). Soapstocks are not as efficiently utilized as neutral fats by broilers in a weight-by-weight basis (Bornstein \& Lipstein, 1963; Freitas et al., 2005). This may be related to an insufficient amount of monoglycerides, and therefore to an incomplete micellar solubilization of free fatty acids, which impairs their absorption (Sklan, 1979).

Although acidulated soapstocks are inexpensive, their inclusion in diets is limited because many poultry nutritionists are still concerned with quality issues and uncertainty of ME values. The lack of a complete knowledge of the production process of acidulated soapstocks, the darkish color and unusual odor are also related to the decision of not including soapstocks in feed formulation. As with other fats, quality control is mandatory prior to including soapstocks in broiler feeding. Unfortunately, many acidulated soapstocks commercially available are composed by a mixture of fat sources and have excessively high levels of moisture, impurities or unsaponifiables, which contribute to impair bird performance. However, promising results have been reported with the use of good quality ASS. Vieira et al. (2002) demonstrated that ASS could be included in diets given from placement to 7 days of age to a level of $8 \%$ without negative effects on performance. Machado et al. (2003) determined ME for Degummed Soybean Oil (DSO) and ASS using broilers with 1 and 5 weeks of age. Energy utilization for DSO and ASS in young chicks was 8,351 and $7,701 \mathrm{kcal} \mathrm{ME} / \mathrm{kg}$, whereas values of 9,314 and 8,559 kcal ME/kg were found for older broilers. Therefore, as long as ASS quality is assured, the decision whether or not to include it in broiler feeds should rely on economical issues only.

Chicks have reduced ability to utilize dietary fat when compared to older birds and this limitation is more evident for fats containing a high proportion of long chain saturated fatty acids (Renner \& Hill, 1960). The poorer absorption of fats by young chicks seems to be related to an impaired enterohepatic circulation of bile salts leading to an inability to fully respond with emulsification when dietary fat increases (Jeanson \& Kellogg, 1992), but also because of a reduced activity of pancreatic lipase in the digestive tract of young birds (Kermanshahi, 1998; Sklan \& Noy, 2000). This reduced ability to digest lipids has been used as an argument to avoid fat supplementation in pre-starter diets. However, utilization of fat by chicks when compared to older broilers is only $10 \%$ reduced (Machado et al., 2003). Therefore, avoiding fat supplementation in the post-hatching feed may not compensate the benefit usually obtained by concentrating energy.

The objective of this study was to investigate the limitations and benefits of including a source of ASS in broiler feeds from placement to 42 days of age when compared to DSO. The response of chicks to increasing levels of feed energy in the first week was also evaluated.

\section{MATERIAL AND METHODS}

A total of 1,600 one-d-old Cobb X Cobb 500 male chicks with a mean weight of $47.8 \mathrm{~g}$ were obtained from a commercial hatchery. Chicks were randomly placed in 40 floor pens $\left(4.0 \mathrm{~m}^{2}\right)$ of a broiler house with concrete floor and new pine shavings litter $(10 \mathrm{~cm})$. Corn-soybean meal diets were provided to the birds throughout the experiment. Feed formulation excluded animal by-products to comply with the European Community requirements for the production of animals for human consumption (CEC, 2000). Mash diets and water were given ad libitum using automatic feeders and bell drinkers. General management was similar to that routinely used in commercial poultry rearing. Temperature was controlled to maintain bird comfort. Lighting was continuous in the first week and 18 hours afterwards.

Chicks were fed pre-starter diet up to 7 days, starter to $21 \mathrm{~d}$, grower to $35 \mathrm{~d}$ and finisher diet to $42 \mathrm{~d}$. All diets were formulated according to NRC (1994) recommendations (Table 2 ). Pre-starter diets were formulated without fat supplementation $(2,870 \mathrm{kcal}$ $\mathrm{ME} / \mathrm{kg}$ ) or added with either DSO or ASS to reach 3,000 or 3,100 kcal ME/kg. Therefore, there were 5 prestarter experimental feeds (treatments) with 8 replicates of 40 chicks each. Energy levels for DSO and ASS were considered to be 8,351 and 7,701 kcal ME/ $\mathrm{kg}$, as previously determined by Machado et al. (2003) in 7-day-old chicks (Table 1).

At 7 days, the original replications of each treatment were equally divided into two groups. Both groups were given diets formulated with the same energy and nutrient contents, but supplemented either with DSO or ASS. Therefore, treatments in the first week were nested in the treatments given from 7 to 42 days, in a total of 10 treatments with 4 replications each. Energy values utilized to formulate the feeds from 7 to 42 days were 9,314 and 8,559 kcal ME/kg for DSO and ASS, respectively (Machado et al., 2003).

Supplemental fat used in this study was obtained from a traditional broiler industry provider. In both 


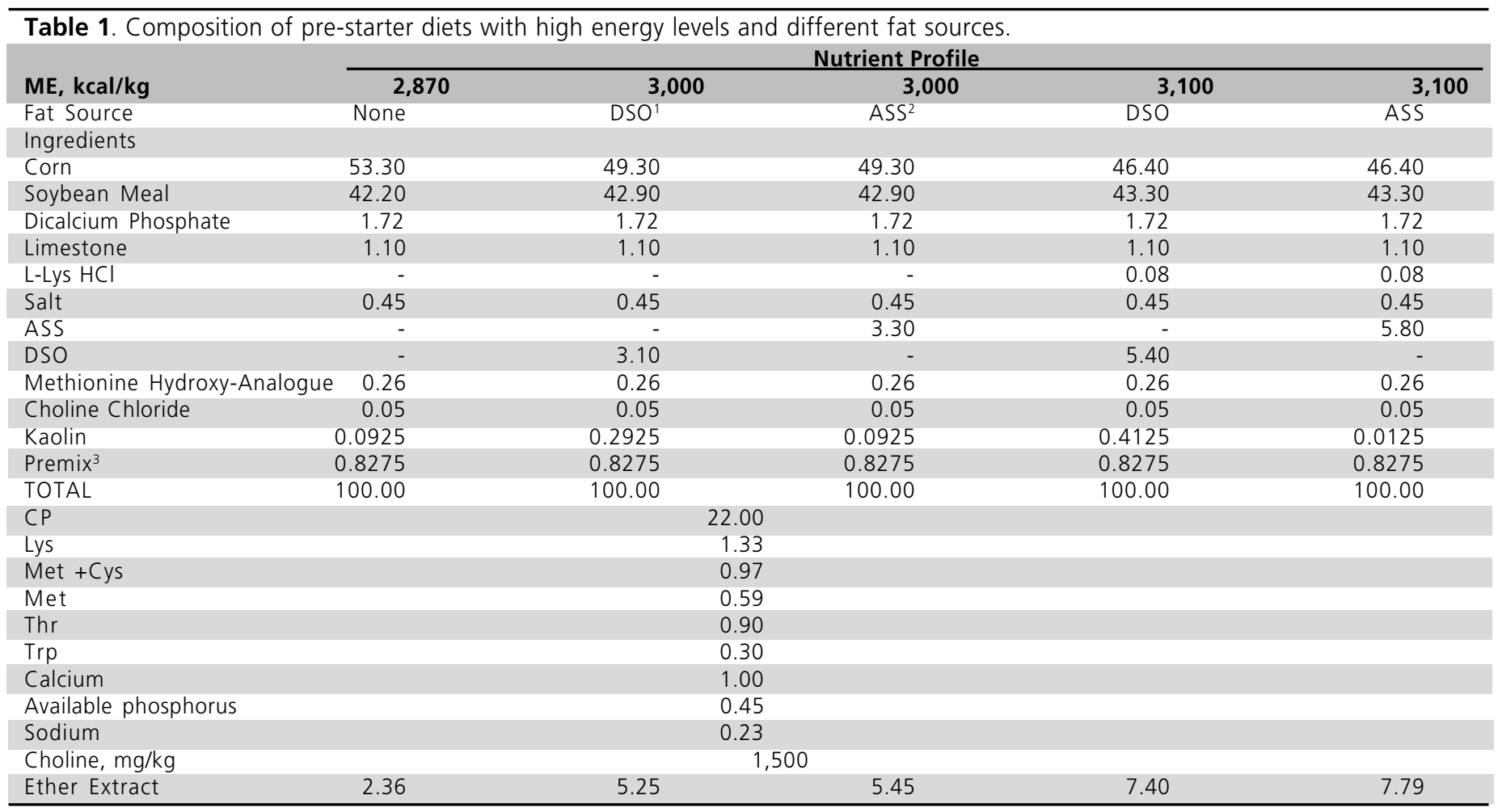

1 - DSO= Degummed Soybean Oil. 2 - ASS = Acidulated Soybean Soapstock. 3 - Supplemented per kg of feed: Vit A, 8,000 IU; Vit D3 2,000 IU; Vit E 30 mg; Vit K3 20 mg; Vit B1, 2.0 mg; Vit B2, 6.0 mg; Vit B6, 2.5 mg; Vit B12, 0.012 mg, Pantothenic Acid, 15 mg; Niacin, 35 mg; Folic Acid, 1.0 mg; Biotin, 0.08 mg; Iron, 100 mg; Copper, 8 mg; lodine, 0.5 mg; Manganese, 80 mg, Selenium, 0.5 mg; Zinc, 70 mg; Salinomycin 60 ppm, Avilamycin 10 ppm.

\begin{tabular}{|c|c|c|c|c|c|c|}
\hline \multirow{3}{*}{$\begin{array}{l}\text { ME kcal/kg } \\
\text { Fat Source }\end{array}$} & \multicolumn{6}{|c|}{ Nutrient Profile } \\
\hline & \multicolumn{2}{|c|}{$\frac{8-21}{3,100}$} & \multicolumn{2}{|c|}{$\frac{22-35}{3,160}$} & \multicolumn{2}{|c|}{$\frac{36-41}{3,250}$} \\
\hline & $\overline{\text { ASS }^{1}}$ & $\overline{\mathrm{DSO}^{2}}$ & ASS & DSO & ASS & DSO \\
\hline \multicolumn{7}{|l|}{ Ingredients } \\
\hline Corn & 54.70 & 54.70 & 66.10 & 66.10 & 66.60 & 66.60 \\
\hline Soybean Meal & 37.40 & 37.40 & 27.00 & 27.00 & 25.40 & 25.40 \\
\hline Dicalcium Phosphate & 1.70 & 1.70 & 1.70 & 1.70 & 1.60 & 1.60 \\
\hline Limestone & 1.15 & 1.15 & 1.05 & 1.05 & 1.00 & 1.00 \\
\hline L-Lys $\mathrm{HCl}$ & 0.13 & 0.13 & 0.33 & 0.33 & 0.30 & 0.30 \\
\hline Salt & 0.40 & 0.40 & 0.40 & 0.40 & 0.40 & 0.40 \\
\hline Methionine Hydroxy Analogue & 0.32 & 0.32 & 0.32 & 0.32 & 0.30 & 0.30 \\
\hline ASS & 3.25 & - & 2.42 & - & 3.70 & - \\
\hline DSO & - & 3.50 & - & 2.60 & - & 4.00 \\
\hline Kaolin & 0.25 & - & 0.18 & - & 0.30 & - \\
\hline Premix ${ }^{3}$ & 0.70 & 0.70 & 0.50 & 0.50 & 0.40 & 0.40 \\
\hline TOTAL & 100.00 & 100.00 & 100.00 & 100.00 & 100.00 & 100.00 \\
\hline$C P$ & \multicolumn{2}{|c|}{22.00} & \multicolumn{2}{|c|}{18.50} & \multicolumn{2}{|c|}{17.50} \\
\hline Lys & \multicolumn{2}{|c|}{1.33} & \multicolumn{2}{|c|}{1.21} & \multicolumn{2}{|c|}{1.14} \\
\hline Met + Cys & \multicolumn{2}{|c|}{0.97} & \multicolumn{2}{|c|}{0.87} & \multicolumn{2}{|c|}{0.82} \\
\hline Met & \multirow{2}{*}{\multicolumn{2}{|c|}{$\begin{array}{l}0.59 \\
0.90\end{array}$}} & \multicolumn{2}{|c|}{0.48} & \multicolumn{2}{|c|}{0.448} \\
\hline Thr & & & \multicolumn{2}{|c|}{0.75} & \multicolumn{2}{|c|}{0.69} \\
\hline $\operatorname{Trp}$ & \multicolumn{2}{|c|}{0.30} & & & \multicolumn{2}{|c|}{0.201} \\
\hline Calcium & \multicolumn{2}{|c|}{1.00} & \multicolumn{2}{|c|}{0.92} & \multirow{2}{*}{\multicolumn{2}{|c|}{0.88}} \\
\hline Available phosphorus & \multicolumn{2}{|c|}{0.45} & \multicolumn{2}{|c|}{0.43} & & \\
\hline Sodium & \multicolumn{2}{|c|}{0.20} & \multicolumn{2}{|c|}{0.20} & \multicolumn{2}{|c|}{0.20} \\
\hline Choline, mg/kg & \multicolumn{2}{|c|}{1,350} & \multicolumn{2}{|c|}{1,200} & & \\
\hline Ether Extract & 5.57 & 5.81 & 5.10 & 5.28 & 6.36 & 6.65 \\
\hline
\end{tabular}

1 - ASS = Acidulated Soybean Soapstock. 2 - DSO= Degummed Soybean Oil. 3 - Supplemented per kg of feed: Vitamins: Vit A, 8,000 IU; Vit D3 2,000 IU; Vit E 30 mg; Vit K3 20 mg; Vit B1, 2.0 mg; Vit B2, 6.0 mg; Vit B6, 2.5 mg; Vit B12, 0.012 mg, Pantothenic Acid, 15 mg; Niacin, 35 mg; Folic Acid, $1.0 \mathrm{mg}$; Biotin, $0.08 \mathrm{mg}$; Iron, 70 mg; Copper, 8 mg; lodine, $0.5 \mathrm{mg}$; Manganese, 80 mg, Selenium, $0.5 \mathrm{mg}$; Zinc, 70 mg; Salinomycin 60 ppm; Avilamycin 10 ppm. 
Vieira SL, Viola ES, Berres J, Olmos AR, Conde ORA, Almeida JG
Performance of Broilers Fed Increased Levels Energy in the Pre-Starter Diet and on Subsequent Feeding Programs Having with Acidulated Soybean Soapstock Supplementation sources, the percentages of moisture, insoluble impurities and unsaponifiable matter were lower than $1 \%$. The fatty acid compositions of DSO and ASS used in this study are presented in Table 3.

\begin{tabular}{|c|c|c|}
\hline \multirow[t]{2}{*}{ Fatty acid } & DSO & ASS \\
\hline & \multicolumn{2}{|c|}{$\%$} \\
\hline C12:0 & - & 0.1 \\
\hline C14:0 & - & 0.2 \\
\hline C 16:0 & 12.6 & 13.0 \\
\hline$C 16: 1 \omega 7$ & - & 0.2 \\
\hline C17:0 & - & 0.1 \\
\hline C18:0 & 4.4 & 3.6 \\
\hline C18:1 $199 \mathrm{~T}$ & - & 3.1 \\
\hline C18:109 & 22.7 & 25.6 \\
\hline $\mathrm{C} 18: 2 \omega 6$ & 52.8 & 48.1 \\
\hline $\mathrm{C} 18: 3 \omega 3 \alpha$ & 6.8 & 5.0 \\
\hline$C 20: 1 \omega 11$ & 0.3 & 0.3 \\
\hline $\mathrm{C} 22: 0$ & 0.4 & 0.5 \\
\hline Total Saturated & 17.4 & 20.6 \\
\hline Monounsaturated & 23.0 & 26.1 \\
\hline Polyunsaturated & 59.6 & 53.1 \\
\hline Free Fatty Acid (as oleic), g/100 g & $<1.0$ & 63.8 \\
\hline
\end{tabular}

1 - Chromatography (Firestone, 1998).

Body weight per pen was evaluated at placement and at 7, 21, 35 and 42 days of age. Feed intake and feed conversion were determined and corrected using the weight of dead birds. At 42 days of age, six birds were randomly taken from each pen, individually tagged, and submitted to 8 hours of feed withdrawal. Each bird was then sacrificed by cervical dislocation, bled for 3 minutes, and the feathers and viscera were manually removed. Carcasses were chilled for 3 hours, allowed to drip for 1 minute and then carefully cut and deboned by a skilled worker as follows: deboned breast (Pectoralis major plus $P$. minor), wings, thighs, drumsticks, and rib cage. The weight of the parts was expressed as percentage of carcass weight.

Litter samples were collected at 7, 21, 35 and 42 days of age for moisture determinations. These measurements were performed to investigate the effects of fat type on litter quality, since there is a generalized concern on the use of ASS by the local industry. Five samples averaging 250 grams were randomly collected from each pen, comprising a circle with $10 \mathrm{~cm}$ of diameter and $2.5 \mathrm{~cm}$ deep. Each sample was dried at $105^{\circ} \mathrm{C}$ until weight became stable. Statistical analysis of litter dry matter was performed using the average value for the 5 samples from each pen.

Data were submitted to statistical analysis using the GLM procedure of SAS (SAS Institute, 2001). An incomplete factorial analysis with 3 levels of energy and two sources of fat was used in the first week. The results from 7 to 42 days were statistically analyzed in a completely randomized design according to a nested factorial arrangement (5 pre-starter diets and 2 fat sources in the subsequent diets). Tukey's test was used to assess differences between means and values of $\mathrm{P}<0.05$ were considered statistically significant.

\section{RESULTS AND DISCUSSION}

Body weight was not affected by treatment at day 7. However, feed intake was reduced with energy increases to $3,100 \mathrm{kcal} / \mathrm{kg}$ and a concurrent improvement on feed conversion was found when energy increased to $3,000 \mathrm{kcal} \mathrm{ME} / \mathrm{kg}$ (Table 4). Significant responses were not observed for fat source nor for its interaction with energy level at this age.

Improvements in feed conversion concomitantly to reductions in feed intake have been reported in broilers

\begin{tabular}{|c|c|c|c|c|c|}
\hline \multirow[t]{2}{*}{ Energy } & \multirow[t]{2}{*}{ Fat Source' } & \multirow[t]{2}{*}{ Body Weight $7 \mathrm{~d}$} & \multicolumn{3}{|c|}{$1-7 d$} \\
\hline & & & Weight Gain, $\mathbf{g}$ & Feed Intake, $\mathbf{g}$ & Feed Conversion \\
\hline & DSO & 181.6 & 133.8 & 141.9 & 1.062 \\
\hline & ASS & 183.9 & 136.3 & 142.1 & 1.047 \\
\hline Probability & & 0.2844 & 0.2273 & 0.9237 & 0.2923 \\
\hline 2870 & & 180.0 & 131.9 & $146.0^{\circ}$ & $1.106^{\circ}$ \\
\hline 3000 & & 183.9 & 136.0 & $142.3^{\text {ab }}$ & $1.048^{\circ}$ \\
\hline 3100 & & 181.5 & 134.1 & $141.8^{\circ}$ & $1.060^{\circ}$ \\
\hline Probability & & 0.2827 & 0.2729 & 0.0298 & 0.0088 \\
\hline 2870 & None & 180.0 & 131.9 & 146.0 & 1.106 \\
\hline 3000 & DSO & 182.4 & 134.4 & 142.1 & 1.057 \\
\hline 3000 & ASS & 185.5 & 137.6 & 142.4 & 1.039 \\
\hline 3100 & DSO & 180.8 & 133.1 & 14.7 & 1.066 \\
\hline 3100 & ASS & 182.3 & 135.0 & 141.8 & 1.054 \\
\hline Probability & & 0.7048 & 0.7436 & 0.9237 & 0.8319 \\
\hline Mean & & 182.2 & 134.4 & 142.8 & 1.055 \\
\hline C.V., \% & & 3.30 & 4.38 & 2.57 & 3.88 \\
\hline
\end{tabular}

Means within a column with no common superscript are significantly different according to Tukey's test. 1 - ASS = Acidulated Soybean Soapstock; DSO = Degummed Soybean Oil. 
fed diets with a wide range of increases in energy (Jackson et al., 1982, Leeson et al., 1996). Replacing calories from carbohydrates with those from fat led to improvements in performance, regardless of environmental temperature (Dale \& Fuller, 1979). Leeson et al. (1996) have shown that broilers control feed intake efficiently based on adjustments on energy intake and therefore, body weight is similar with low and high energy diets; however, feed efficiency was impaired as energy was reduced in the diet. Therefore, it has been widely accepted that fat has an extra caloric effect, which has a positive impact on feed conversion that is greater than the amount of energy provided by fat per se.

Improved response to increase in feed energy at an early age was observed in this study. Feed intake decreased as energy increased. However, there was a limitation on the improvement of feed conversion at $3,000 \mathrm{kcal} \mathrm{ME} / \mathrm{kg}$. This limitation is not usually seen at older ages and may be due to a deficient fat utilization in younger birds (Carew et al., 1972; Jeanson \& Kellogg, 1992; Kermanshahi, 1998; Polin \& Hussein, 1982; Renner \& Hill, 1960; Sklan \& Noy, 2000). However, chicks are older than 2 weeks in most of the published reports on fat utilization. Therefore, a direct analogy with results obtained with one-weekold chicks is possibly limited.

Acidulated soapstock is known to have a reduced utilization by broilers when compared to neutral fats, such as DSO (Sklan, 1979). Lower absorption (9\%) and poorer feed conversion (6\%) were observed when neutral fat was replaced in a weight-by-weight basis by acidulated soapstock (Bornstein \& Lipstein, 1963; Artman, 1964; Lipstein \& Bornstein, 1968). In the present study, feed formulation used ME values for DSO 8\% greater than ASS, as previously estimated (Machado et al., 2003). Therefore, the non-significant effect of fat source in the first week is an indication that the ME values compensated for the existing differences in fat utilization. It is also accepted that both types of fats were qualitatively adequate.

Except for body weight at 21 and 35 days, there were no differences in performance or the yield of the carcass and commercial parts related to the source of fat in the feed. Differences in feed energy are expected to affect feed efficiency more markedly than body weight gain. Therefore, improved body weight as observed in 21- and 35-day broilers fed ASS compared to those fed DSO may be related to other benefits arising from ASS. In the process of producing soybean oil for human consumption, many nutrients and other substances frequently driven to the residue that later originates ASS are considered to have a positive impact in animal health. For example, vitamin E found in ASS in the present study was almost four times higher than what is usually found in soybean fat (34.3 mg of alpha tocopherol/100 g) (USDA, 2004). Besides, ASS usually contains lecithin, which is a rich source of choline, and flavonoids that are important for human and animal health; these nutrients are not found in soybean fat (USDA, 2004; Yang et al., 2001).

Litter dry matter was determined due to concerns on ASS quality expressed by personnel from the industry located in the south of Brazil. These concerns are related to the limited knowledge on ASS composition and source, but also to its frequent adulteration. Low-quality fats are expected to negatively impact feed passage through the intestinal tract and, therefore, affect the total moisture of excreta. Increasing concentrations of saturated free fatty acids in broiler feed decreased the ME of added fat, whereas unsaturated free fatty acids did not significantly affect the ME value of added fat (Vila \& Esteve-Garcia, 1996). However, Ouart et al. (1992) could not find effects on the feed passage rate when good quality fat was added in total feed at levels as high as $5 \%$. The ASS used in this study was of good quality and presented a fatty acid profile very similar to that of DSO (Table 3). Treatments used herein did not affect litter dry matter $(P>0.05)$. The values of dry matter percentage were considered adequate for first crop pine shavings used as litter material and the density and bird weight used in the present study $(80.8,68.0$, 63.4 and 67.34 for $7,21,35$ and 42 days, respectively).

Overall responses of DSO and ASS from 7 to 42 days were similar and therefore it is assumed that both fat sources may be interchangeable in broiler feeds to the levels used in this study. Thus, the decision should be exclusively based on price. Results presented in Tables 4 to 8 do not provide indications that there were residual effects of treatments given in the first week on responses obtained later on in the study.

The findings of this study corroborate the ME values of DSO and ASS used in feed formulation for early posthatching chicks as well as for older broilers. Besides, the results were similar to those obtained by Freitas et al. (2005). Therefore, as long as the quality is adequate, the use of ASS is a viable alternative for fat supplementation of broiler feeds. This is especially important when formulating vegetarian feeds, in which soybean oil, an expensive source, is included at high levels. 


\begin{tabular}{|c|c|c|c|c|c|}
\hline $\begin{array}{l}\text { Energy } \\
1 \text { to } 7 \mathrm{~d}\end{array}$ & & $\begin{array}{l}\text { Fat Source }{ }^{1} \\
7 \text { to } 42 d\end{array}$ & $21 d$ & $35 \mathrm{~d}$ & $42 d$ \\
\hline & & ASS & $926^{a}$ & $2,030^{a}$ & 2,671 \\
\hline & & DSO & $901^{b}$ & $1,986^{b}$ & 2,630 \\
\hline Probability & & & 0.0219 & 0.0131 & 0.1285 \\
\hline 2870 & None & ASS & 925 & $2,049^{b}$ & 2,727 \\
\hline 3000 & ASS & ASS & 924 & $2,047^{b}$ & 2,708 \\
\hline 3000 & DSO & ASS & 942 & $2,020^{c}$ & 2,611 \\
\hline 3100 & ASS & ASS & 934 & $2,009^{d}$ & 2,626 \\
\hline 3100 & DSO & ASS & 903 & $2,022^{c}$ & 2,680 \\
\hline 2870 & None & DSO & 902 & $1,951^{\dagger}$ & 2,623 \\
\hline 3000 & ASS & DSO & 897 & $1,967^{e}$ & 2,610 \\
\hline 3000 & DSO & DSO & 886 & $1,948^{f}$ & 2,555 \\
\hline 3100 & ASS & DSO & 909 & $2,009^{d}$ & 2,679 \\
\hline 3100 & DSO & DSO & 911 & $2,058^{a}$ & 2,684 \\
\hline Probability & & & 0.2851 & 0.0219 & 0.0515 \\
\hline Mean & & & 913 & 2,008 & 2,651 \\
\hline C.V., \% & & & 3.76 & 2.30 & 2.82 \\
\hline
\end{tabular}

Means within a column with no common superscript are significantly different according to Tukey's test. 1 - ASS = Acidulated Soybean Soapstock; DSO= Degummed Soybean Oil.

\begin{tabular}{|c|c|c|c|c|c|}
\hline \multirow[t]{3}{*}{$\begin{array}{l}\text { Energy } \\
1 \text { to } 7 \mathrm{~d}\end{array}$} & \multicolumn{2}{|c|}{$\begin{array}{l}\text { Fat Source } 7 \text { to } 21 d \\
7 \text { to } 42 d\end{array}$} & \multicolumn{3}{|c|}{21 to $35 \mathrm{~d} 35$ to $42 \mathrm{~d} 1$ to $42 \mathrm{~d}$} \\
\hline & ASS & 1,038 & 1,988 & 1,392 & 4,531 \\
\hline & DSO & 1,009 & 1,950 & 1,365 & 4,516 \\
\hline Probability & & 0.3885 & 0.2927 & 0.2776 & 0.7753 \\
\hline 2870 None & ASS & 1,043 & 2,032 & 1,390 & 4,567 \\
\hline 3000 ASS & ASS & 1,040 & 1,973 & 1,431 & 4,518 \\
\hline 3000 DSO & ASS & 1,077 & 1,955 & 1,430 & 4,684 \\
\hline 3100 ASS & ASS & 1,064 & 1,928 & 1,330 & 4,487 \\
\hline 3100 DSO & ASS & 964 & 1,859 & 1,378 & 4,424 \\
\hline 2870 None & DSO & 1,045 & 1,941 & 1,432 & 4,556 \\
\hline 3000 ASS & DSO & 918 & 2,033 & 1,405 & 4,592 \\
\hline 3000 DSO & DSO & 1,031 & 1,983 & 1,283 & 4,422 \\
\hline 3100 ASS & DSO & 1,008 & 1,975 & 1,356 & 4,530 \\
\hline 3100 DSO & DSO & 1,045 & 2,010 & 1,347 & 4,552 \\
\hline Probability & & 0.2871 & 0.7672 & 0.1396 & 0.4065 \\
\hline Mean & & 1,024 & 1,969 & 1,378 & 4,524 \\
\hline C.V., \% & & 10.19 & 6.02 & 5.11 & 3.76 \\
\hline
\end{tabular}

Means within a column with no common superscript are significantly different according to Tukey's test. 1 - ASS = Acidulated Soybean Soapstock; DSO = Degummed Soybean Oil.

\section{CONCLUSIONS}

A ME value of $3,000 \mathrm{kcal} / \mathrm{kg}$ is recommended in pre-starter diets for broilers. Acidulated soybean soapstock is well tolerated and may be used as a source of vegetable fat in diets for broilers.

\section{REFERENCES}

Artman NR. Interactions of fats and fatty acids as energy sources for the chick. Poultry Science 1964; 43:994-1004.

\begin{tabular}{|c|c|c|c|c|c|}
\hline \multicolumn{6}{|c|}{$\begin{array}{l}\text { Table } 7 \text { - Feed convers } \\
\text { in the pre-starter diets } \\
\text { days of age. } \\
\text { Energy Fat Source }{ }^{1}\end{array}$} \\
\hline $\begin{array}{l}\text { Energy } \\
1 \text { to } 7 \mathrm{~d}\end{array}$ & $\begin{array}{l}\text { at source } \\
7 \text { to } 42 \mathrm{~d}\end{array}$ & 7 to $21 \mathrm{~d}$ & 21 to 35 & 35 to 42 & 1 to $42 \mathrm{~d}$ \\
\hline & ASS & 1.392 & 1.834 & 2.205 & 1.755 \\
\hline & DSO & 1.409 & 1.767 & 2.123 & 1.722 \\
\hline \multicolumn{2}{|l|}{ Probability } & 0.7065 & 0.0548 & 0.3542 & 0.0997 \\
\hline 2870 None & e ASS & 1.399 & 1.807 & 2.053 & 1.704 \\
\hline 3000 ASS & ASS & 1.400 & 1.757 & 2.182 & 1.699 \\
\hline 3000 DSO & ASS & 1.419 & 1.814 & 2.524 & 1.790 \\
\hline 3100 ASS & ASS & 1.413 & 1.792 & 2.172 & 1.740 \\
\hline 3100 DSO & ASS & 1.328 & 1.662 & 2.098 & 1.679 \\
\hline 2870 None & e DSO & 1.446 & 1.848 & 2.134 & 1.770 \\
\hline 3000 ASS & DSO & 1.302 & 1.904 & 2.189 & 1.792 \\
\hline 3000 DSO & DSO & 1.466 & 1.867 & 2.111 & 1.763 \\
\hline 3100 ASS & DSO & 1.393 & 1.799 & 2.025 & 1.721 \\
\hline 3100 DSO & DSO & 1.437 & 1.754 & 2.158 & 1.728 \\
\hline \multicolumn{2}{|l|}{ Probability } & 0.6689 & 0.3206 & 0.3200 & 0.0670 \\
\hline \multicolumn{2}{|c|}{ Mean 1.4001 .800} & 2.165 & 1.739 & & \\
\hline \multicolumn{2}{|c|}{ C.V., $\% 10.635 .79$} & 12.53 & 3.23 & & \\
\hline
\end{tabular}

Means within a column with no common superscript are significantly different according to Tukey's test. 1 - ASS = Acidulated Soybean Soapstock; DSO= Degummed Soybean Oil.

Bornstein S, Lipstein B. Some unusual waste vegetable oil as fat supplements in practical broiler rations. World's Poultry Science Journal 1963; 19:172-184.

Carew LB, Machemer Jr., RH, Sharp RW, Foss DC. Fat absorption by the very young chick. Poultry Science 1972; 51:738-742.

CEC. Council Regulation 2000/766 concerning certain protection measures with regard to transmissible spongiform encephalopathies and the feeding of animal protein. Official Journal of European Communities 2000; 43(L306):32-33.

Dale NM, Fuller HL Effects of diet composition on feed intake and growth of chicks under heat stress. I. Dietary fat levels. Poultry Science 1979; 58:1529-1534.

Firestone D. Official methods and recommended practices of the American Oil Chemists Society. $5^{\text {th }}$ ed. Champaign:AOCS; 1998. v.1-2.

Freitas ER, Sakomura NK, Neme R, Santos AL. Valor enegético do óleo ácido de soja para aves. Pesquisa Agropecuária Brasileira 2005: 40:241-246

Hofmann AF, Borgström B. Physico-chemical state of lipids in intestinal content during their digestion and absorption. Federation Proceedings 1962; 21:43-50.

Jackson S, Summers JD, Leeson S. Effect of dietary protein and energy on broiler performance and production costs. Poultry Science $1982 ; 61: 2232-2240$

Jeanson SE, Kellogg TF. Ontogeny of taurocholate accumulation in the terminal ileal mucosal cells of young chicks. Poultry Science 1992; 71:367-372.

Kermanshahi $\mathrm{H}$. The potential of dietary lipases to improve fat utilization in young birds [PhD]. Saskatoon (CA):University of 
Saskatchewan; 1998.

Leeson S, Caston L, Summers JD. Broiler response to diet energy. Poultry Science 1996; 75:529-535.

Lipstein B, Bornstein S. Lack of interference between dietary acidulated soybean soapstock and calcium in chicks and laying hens. Poultry Science 1968; 47:1905-1911.

Machado LP, Vieira SL Quadros VR. Source Level and age differences in fat utilization by broilers. Poultry Science 2003; 82(Abst.):39.

National Research Council. Nutrient requirements for poultry. $9^{\text {th }}$ ed. Washington (DC): National Academy Press; 1994.

Ouart MD, Damron BL, Martin FG, Christmas RB, Sloan DR. Effects of poultry fat and yellow grease on broiler performance and profitability. Poultry Science 1992; 71:821-828.

Polin D, Hussein TH. The effect of bile acid on lipid and nitrogen retention, carcass composition, and dietary metabolizable energy in very young chicks. Poultry Science 1982; 61:1697-1707.

Renner R, Hill FW. The utilization of corn oil, lard, and tallow by chickens of various ages. Poultry Science 1960; 39:849-854.

SAS Institute. SAS user's guide. Cary (NC):SAS Institute; 2001.

Sklan D. Digestion and absorption of lipids in chicks fed triglycerides or free fatty acids: synthesis of monoglycerides in the intestine. Poultry Science 1979; 58:885-889.

Sklan D. Fat and carbohydrate use in posthatch chicks. Poultry Science 2003; 82:117-122.

Sklan D, Noy Y. Hydrolysis and absorption in the small intestines of posthatch chicks. Poultry Science 2000; 79:1306-1310.

USDA, 2004 Capturado em 20 de julho de 2004. Disponível em: http://www.ars.usda.gov

Vieira SL, Ribeiro AML, Kessler AM, Fernandes LM, Ebert AR, Eichner G. Utilização da energia de dietas para frangos de corte formuladas com óleo ácido de soja. Brazilian Journal of Poultry Science 2002; $4: 127-131$

Vila B, Esteve-Garcia E. Studies on acid oils and fatty acids for chickens. II. Effect of free fatty acid content and degree of saturation of free fatty acids and neutral fat on fatty acid digestibility. British Poultry Science 1996; 37:119-130.

Yang CS, Landau JM, Huang MT, Newmark HL. Inhibition of carcinogenesis by dietary polyphenolic compounds. Annual Review of Nutrition 2001; 21:81-406. 


\section{Novidade!}

Livro

\section{MANEJO DE MATRIZES \\ DE CORTE \\ $2^{a}$ Edição}

Editores:

Marcos Macari

Ariel Antônio Mendes

Mais uma realização

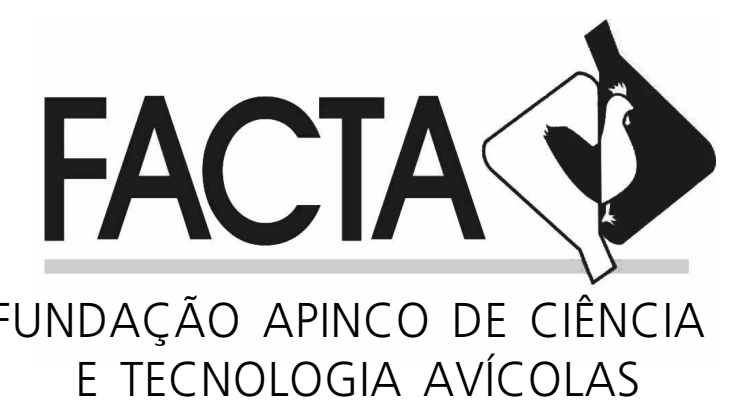

